(2) Open Access Full Text Article

\title{
Case of femoral diaphyseal stress fracture after long-term risedronate administration diagnosed by iliac bone biopsy
}

This article was published in the following Dove Press journal:

Therapeutics and Clinical Risk Management

29 April 2013

Number of times this article has been viewed

\section{Takashi Nagai \\ Keizo Sakamoto \\ Koji Ishikawa \\ Emi Saito \\ Takuma Kuroda \\ Katsunori Inagaki}

Department of Orthopaedic Surgery, Showa University School of Medicine, Shinagwa-ku, Tokyo, Japan
Correspondence: Takashi Nagai Department of Orthopaedic Surgery, Showa University School of Medicine, I-5-8 Hatanodai, Shinagawa-ku, Tokyo 142-8666, Japan

$\mathrm{Tel}+8 \mathrm{I} 337848543$

Fax +8I 337849005

Email nagai.babby@gmail.com
Abstract: Bisphosphonate excessively inhibits bone resorption and results in pathological fracture of the femur or ilium. The subject of this study was administered risedronate for 7 years; we suspected an easy fracture of the femoral diaphysis. In this study, we report the results of this patient's bone biopsy and bone morphometric analysis. A 76-year-old female patient presented with right femoral pain. Bone mineral density of the anteroposterior surface of the 2nd to 4th lumbar vertebrae (L2-L4) was decreased and levels of bone turnover markers were high. Therefore, we initiated treatment with risedronate. As she continued the medication, urinary levels of cross-linked N-terminal telopeptides of type I collagen and alkaline phosphatase (bone-type isozyme) were found to be within the normal ranges. After 7 years of administration, the patient experienced pain when she put weight on the right femur and right femoral pain while walking. Plain radiographic examination revealed polypoid stress fracture-like lesions on the right femoral diaphysis and on the slightly distal-lateral cortical bone. Similar lesions were observed on magnetic resonance imaging and bone scintigraphy. We suspected severely suppressed bone turnover. Bone biopsy was obtained after labeling with tetracycline, and bone morphometric analysis was performed. On microscopic examination, slight double tetracycline labeling was observed. The trabeculae were narrow, and the numbers of osteoblasts and osteoclasts were decreased. Further, rates of bone calcification and bone formation were slow. Hence, we diagnosed fracture as a result of low turnover osteopathy. Risedronate was withdrawn, and Vitamin $\mathrm{D}_{3}$ was administered to improve the bone turnover. At 6 months, abnormal signals on magnetic resonance imaging had decreased and her pain while walking or undergoing the stress test disappeared as well. Thus, long-term administration of bisphosphonates may lead to easy fracture, although bone turnover markers were observed to be within the normal range. During bisphosphonate administration, physicians need to monitor closely and treat their patients for any pain experienced in the femoral region while walking or undergoing a stress test.

Keywords: bisphosphonate, severely suppressed bone turnover, risedronate

\section{Introduction}

Previous studies have reported that treatment with bisphosphonates, such as alendronate or risedronate, for osteoporosis excessively suppress bone resorption and result in a high tendency for femoral or iliac fractures. ${ }^{1,2}$ We report a case involving a suspected femoral diaphyseal stress fracture detected after long-term treatment with risedronate. The patient was initially treated with risedronate for 7 years, and bone metabolic turnover was excessively suppressed. We also present the bone biopsy results and bone morphology measurements. 


\section{Case report}

A 76-year-old woman presenting with right femoral pain visited our hospital in April 2004, and was treated for osteoporosis. Laboratory tests revealed a frontal lumbar spine bone density of $0.492 \mathrm{~g} / \mathrm{cm}^{2}$ ( $46 \%$ of young adult mean, $61 \%$ of adult mean) and urine cross-linked $\mathrm{N}$-terminal telopeptide of type I collagen (NTX) of $144 \mathrm{nMBCE} / \mathrm{mMCr}$. A diagnosis of osteoporosis with high bone metabolism was subsequently made. Treatment with risedronate was initiated and maintained for seven years. Bone density at the lumbar spine, femur, and radius increased after treatment. The patient's urine NTX value was $20-40 \mathrm{nMBCE} / \mathrm{mMCr}$ (nanomllar bone collagen equivalents/milimolar creatinine) and her bone-specific alkaline phosphatase was $10-30 \mu \mathrm{g} / \mathrm{L}$ while on oral risedronate $2.5 \mathrm{mg}$ /day.

A plain X-ray was performed in November 2011 because the patient experienced pain in her right femoral region while walking or applying stress on her right femur. We detected a stress fracture-like lesion that formed an eminence distal to the lateral cortical bone of the right femoral diaphysis (Figure 1A). We suspected an atypical femoral fracture as a result of suppression of bone metabolic turnover. The patient was hospitalized in December 2011 for further investigations. We explained the risks of bone fractures induced by risedronate administration to the patient and her family, and written consent was obtained. We advised her to take the drug until the day before biopsy so that we could evaluate the bone biopsy results and determine if bone turnover was suppressed.

The patient's height and body weight were $132.4 \mathrm{~cm}$ and $43.5 \mathrm{~kg}$, respectively, and her body mass index was 24.8 . The patient did not experience pain or restricted motion during hip or knee movements. Although no redness, swelling, or warmth of the skin over the femur or abnormal signs on the left and right circumferences were observed, she experienced pain when stress was applied to the right femoral diaphysis.

\section{Biochemical tests during hospitalization}

Biochemical analysis revealed albumin $4.0 \mathrm{~g} / \mathrm{dL}$, calcium $8.8 \mathrm{mg} / \mathrm{dL}$ phosphate $2.9 \mathrm{mg} / \mathrm{dL}$, magnesium $2.1 \mathrm{mg} / \mathrm{dL}$, and alkaline phosphatase $159 \mathrm{IU} / \mathrm{L}$. All bone turnover marker levels were in the normal range: early morning secondary urine NTX $26.4 \mathrm{nMBCE} / \mathrm{mMCr}$, bone-specific alkaline phosphatase $9.9 \mu \mathrm{g} / \mathrm{L}$, osteocalcin $6.6 \mathrm{ng} / \mathrm{mL}$, tartrateresistant acid phosphatase (TRACP) $5 \mathrm{~b} 358 \mathrm{mU} / \mathrm{dL}$, and undercarboxylated osteocalcin $3.82 \mathrm{ng} / \mathrm{mL}$.

\section{Findings of imaging}

Magnetic resonance imaging revealed low T1 signal with a $2 \mathrm{~cm}$ width, abnormally high $\mathrm{T} 2$ signals, and short inversion time inversion recovery for the right femoral diaphysis (Figure 1B). Bone scintigraphy revealed an abnormal accumulation in the distal right femoral diaphysis (Figure 1C). No abnormal accumulations were observed in any other regions.

\section{Clinical course}

We suspected a stress fracture of the femur caused by excessive suppression of bone turnover because the diagnostic images revealed no typical neoplastic lesions. We performed a bone biopsy of the right ilium in December 2011 after double tetracycline (Achromycin VTM; Wyeth Canada Inc, Montreal, Canada) labeling. Achromycin V $250 \mathrm{mg}$ was administered
A

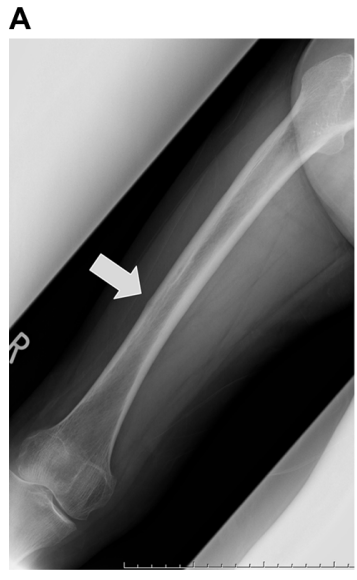

B

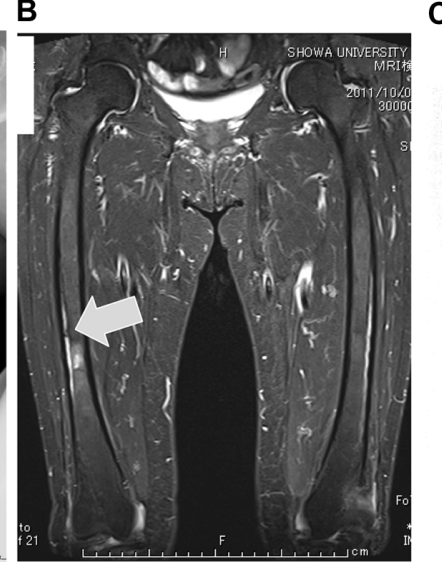

C

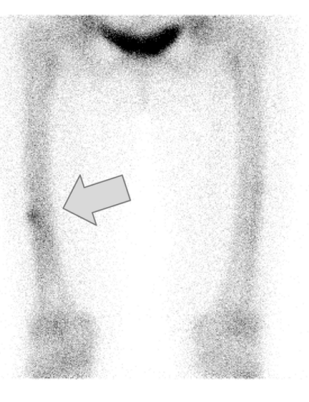

Figure I Findings on imaging.

Notes: (A) Plain X-ray images show the apophysis of the bone on the lateral side of the femoral diaphysis. (B) Magnetic resonance T2-weighted fat-suppressed image shows the high signal intensity at the diaphysis. (C) Bone scintigraphy reveals an accumulation in the right femoral diaphysis. 


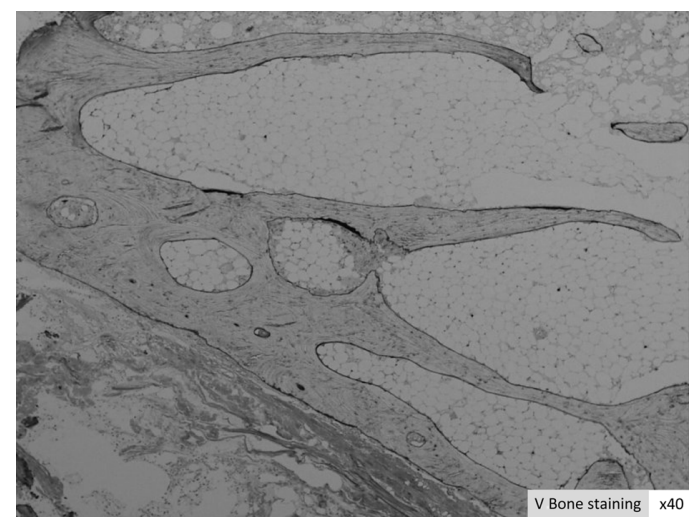

Figure 2 MMA resin-embedded $\mathrm{V}$ bone stain.

Notes: A slight double-labeling of tetracycline can be observed. The trabeculae were narrow, and both osteoblasts and osteoclasts were decreased.

Abbreviations: MMA, methyl methacrylate; $\mathrm{V}$ bone, villanueva bone.

as four capsules twice daily for 2 days and withdrawn for 10 days. The drug was readministered at the same dose for 2 days and then stopped for 5 days. Subsequently, bone biopsy samples were obtained and examined. Pathological investigation revealed a slight tetracycline double label. The trabeculae were narrow, and the number of osteoblasts and osteoclasts had decreased (Figure 2). Although the bone resorption parameters were close to the normal range, bone calcification and bone formation rates were low (Table 1). We assumed that her bone turnover was low, so we discontinued risedronate and initiated vitamin $\mathrm{D}_{3}$ therapy. At 6-month follow-up (the time of writing), there were fewer regions of abnormal accumulation on magnetic resonance imaging and her pain while walking had disappeared.

\section{Discussion}

Since 2005, a few studies have reported that bone turnover may become excessively suppressed after administration of bisphosphonates, resulting in an increased risk of femoral and iliac fractures. ${ }^{1,2}$ The patient in this study had been on risedronate therapy since 2004, which was continued for more than 7 years. Laboratory data revealed that her urine NTX was 20-40 nMBCE/mMCr and bone-specific alkaline phosphatase was $10-30 \mu \mathrm{g} / \mathrm{L}$, indicating that bone resorption was not excessively suppressed. A diagnosis of stress fracture rather than severely suppressed bone turnover should have been suspected. However, the bone morphology measurements from the iliac biopsy performed in 2011 revealed that bone turnover was markedly decreased. This suggests that long-term administration of bisphosphonates may lead to easy fractures even if bone turnover markers are in the normal range. Femoral pain while walking or that induced by a load should be carefully monitored during treatment with bisphosphonates. Femoral pain in elderly patients occurs because of a genetic predisposition to neuralgia as a result

Table I Bone morphology measurement results

\begin{tabular}{|c|c|c|c|}
\hline Parameter & Unit & Measurements & Normal value \\
\hline Bone mass & $\%$ & & \\
\hline Bone quality & $\%$ & $14.99 \uparrow$ & $11.0 \pm 1.8$ \\
\hline Trabecular bone width & $\mu \mathrm{m}$ & II $3.49 \downarrow$ & $135.5 \pm 7.5$ \\
\hline Unit width trabecular bone & $\mu \mathrm{m}$ & Not measured & $42.0 \pm 2.0$ \\
\hline The amount of osteoid tissue & $\%$ & 0.33 & $0.1 \sim 1.0$ \\
\hline Osteoid & $\%$ & $2.2 \uparrow$ & $1.6 \pm 0.4$ \\
\hline \multicolumn{4}{|l|}{ Osteoid bone mass } \\
\hline Osteoid surface & $\%$ & $20.55 \uparrow$ & $12.8 \pm 2.2$ \\
\hline Osteoid width & $\mu \mathrm{m}$ & 5.96 & $6.4 \pm 0.8$ \\
\hline \multicolumn{4}{|l|}{ Absorption } \\
\hline Absorbing surface & $\%$ & 3.79 & $3.0 \pm 1.0$ \\
\hline Osteoclast number & $\mathrm{N} / \mathrm{mm}$ & 0.28 & \\
\hline The amount of fiber & $\%$ & 0 & 0 \\
\hline \multicolumn{4}{|l|}{ Calcification } \\
\hline Bone calcification rate & $\mu \mathrm{m} /$ day & $0.27 \downarrow$ & $0.477 \pm 0.078$ \\
\hline Double-labeled surface & $\%$ & 0.36 & \\
\hline Dual-labeled surface & $\%$ & 1.97 & \\
\hline Bone formation rate (surface trabecular bone) & $\mathrm{mm}^{3} / \mathrm{mm}^{2} / \mathrm{yr}$ & $0.001 \downarrow$ & $0.01 \pm 0.008$ \\
\hline Bone formation rate (bone mass) & $\% / y e a r$ & $2.32 \downarrow$ & $16.2 \pm 12.5$ \\
\hline Frequency activation & $\mathrm{N} /$ year & Not calculated & 0.35 \\
\hline
\end{tabular}

Notes: The data indicate that osteoid was increased and bone formation was decreased. Arrows show increase/decrease compared with normal value. Normal value is the mean \pm standard deviation. 
of osteoarthritis at the lumbar spine, lumbar spinal canal stenosis, or radiating pain accompanied by coxarthrosis or gonarthrosis. A plain X-ray and magnetic resonance imaging are required in such cases. In our case, we detected a stress fracture-like lesion before a bone fracture occurred because the patient complained of pain induced by axial load (walking), after which we performed a femoral stress test. Risedronate was discontinued, and vitamin $\mathrm{D}_{3}$ therapy was initiated until her bone turnover returned to near normal at the time of writing. Treatment may be switched to selective estrogen receptor modulators, which suppress bone turnover to a lesser extent than bisphosphonates. Parathyroid hormone drugs that stimulate bone formation may also be used. ${ }^{3}$ Osteosynthesis using an intramedullary rod can be used for preventing bone fractures. ${ }^{4}$

Atypical femoral fractures with severely suppressed bone turnover are associated with the following conditions and characteristics: affected patients are usually on long-term bisphosphonate therapy, particularly alendronate; the fractures are transverse with spikes; fractures occur on the opposite side of the femur, hyperplasia of the cortical bone, or bone scintigraphy revealing abnormal accumulation in other regions; femoral pain develops as a precursor symptom before bone fractures; mild external force induces fractures; and bone union is delayed. ${ }^{5}$ This case exhibited most of these characteristics except for complete bone fracture.

It is important to monitor for excessive suppression of bone turnover caused by bisphosphonates. In our hospital, no cases of bone fractures with severely suppressed bone turnover or stress fractures have been encountered. Schilcher et al reported that the bisphosphonate group in their study showed high odds ratios. Subjects in their atypical femoral fracture group showed a 33.3-fold higher rate of atypical femoral fracture and a 1.3-fold higher rate per 100 days of bisphosphonate administration than those in the nonbisphosphonate group. In contrast, five cases had an increased absolute fracture risk with bisphosphonate treatment per 10,000 patients per year. ${ }^{6}$ Bisphosphonates should only be administered to patients who cannot be treated with other drugs; however, this cannot rule out the risk of severely suppressed bone turnover. Appropriate use of bisphosphonates should be determined after considering the risks and benefits for each patient with osteoporosis.

Histomorphometric analysis of bone biopsy samples in this patient revealed that bone resorption was normal and bone formation was inhibited. We attempted to understand clearly the status of bone resorption and formation in bones in vivo to elucidate appropriate prophylaxis for severely suppressed bone turnover. However, in this case, bone metabolism marker levels just before bone biopsy (bonespecific alkaline phosphatase, osteocalcin, urinary NTX, tartrate-resistant acid phosphatase 5b, and undercarboxylated osteocalcin) and the status of bone resorption and formation in the ilium were not consistent with overall bone metabolism marker levels, so monitoring was difficult. Even if bone metabolism markers are within the normal range, one cannot be overconfident. Bisphosphonates can be withdrawn after use for at least 5 years, ${ }^{3}$ but atypical femur fractures within a year of bisphosphonate withdrawal have also been reported. ${ }^{6,7}$ Therefore, the timing of bisphosphonate withdrawal is important. Symptoms such as upper leg pain and femoral discomfort are likely to be present before an atypical femur fracture, so listening to the patient's complaints is considered an important measure in fracture prevention.

\section{Conclusion}

A patient on risedronate therapy for more than 7 years presented with femoral diaphyseal stress fracture-like symptoms, which were considered to be indicative of severely suppressed bone turnover. Bone morphology measured after a biopsy of the ilium showed that her bone turnover was indeed markedly decreased.

\section{Acknowledgment}

The authors thank Noriaki Yamamoto, Niigata Bone Science Institute, who provided generous support for the labeling method and bone morphology measurements.

\section{Disclosure}

The authors report no conflicts of interest in this work.

\section{References}

1. Kwek EB, Goh SK, Koh JS, Png MA, Howe TS. An emerging pattern of subtrochanteric stress fractures: a long-term complication of alendronate therapy? Injury. 2008;39:224-231.

2. Odvina CV, Zerwekh JE, Rao DS, Maalouf N, Gottschalk FA, Pak CY. Severely suppressed bone turnover: a potential complication of alendronate therapy. J Clin Endocrinol Metab. 2005;90:1294-1301.

3. Watts NB, Diab DL. Long-term use of bisphosphonates in osteoporosis. J Clin Endocrinol Metab. 2010;95:1555-1565.

4. Shane E, Burr D, Ebeling PR, et al. Atypical subtrochanteric and diaphyseal femoral fractures: Report of a Task Force of the American Society for Bone and Mineral Research. J Bone Miner Res. 2010;25:2267-2294.

5. Nieves JW, Cosman F. Atypical subtrochanteric and femoral shaft fractures and possible association with bisphosphonates. Curr Osteoporos Rep. 2010;8:34-39.

6. Schilcher J, Michaëlsson K, Aspenberg P. Bisphosphonate use and atypical fractures of the femoral shaft. $N$ Engl J Med. 2011;364: $1728-1737$.

7. Giusti A, Hamdy NA, Papapoulos SE. Atypical fractures of the femur and bisphosphonate therapy; a systematic review of case/case series studies. Bone. 2010;47:169-180. 
Therapeutics and Clinical Risk Management

Dovepress

\section{Publish your work in this journal}

Therapeutics and Clinical Risk Management is an international, peerreviewed journal of clinical therapeutics and risk management, focusing on concise rapid reporting of clinical studies in all therapeutic areas outcomes, safety, and programs for the effective, safe, and sustained use of medicines. This journal is indexed on PubMed Central, CAS
EMBase, Scopus and the Elsevier Bibliographic databases. The manuscript management system is completely online and includes a very quick and fair peer-review system, which is all easy to use. Visit http://www.dovepress.com/testimonials.php to read real quotes from published authors.

Submit your manuscript here: http://www.dovepress.com/therapeutics-and-clinical-risk-management-journal 